\title{
Bright red electroluminescence in diffused porous silicon $p-n$ junction
}

\author{
V K JAIN, AMITA GUPTA, A KUMAR, G K SINGHAL, O P ARORA, \\ T SRINIVASAN, D S AHUJA, P P PURI and VIKRAM KUMAR \\ Solid State Physics Laboratory, Lucknow Road, Delhi 110054, India \\ MS received 3 June 1993
}

Abstract. We report the first operation of light emitting $p-n$ junction diode in porous silicon fabricated by diffusion.

Keywords. Electroluminescence: porous-silicon $p-n$ junction

The recent demonstration (Canham 1990) of visible photoluminescence from porous silicon (PSi) at room temperature has received worldwide attention. Several attempts have been reported for obtaining electroluminescence from this material. Detailed structural and optical investigations of the properties of this material have been reviewed recently by Searson et al (1992). The porosity is commonly generated by an electrochemical process which results in a nanometer size silicon ligament network. There have been different explanations invoking quantum size effects and formation of hydride layers for the observation of photoluminescence in this material.

Here we report two significant results which are likely to open up this material for optoelectronic applications. Firstly we have observed photoluminescence from the $p-n$ junctions formed by diffusion of counter dopant. Secondly, we report the fabrication of electroluminescent diode with stable optical characteristics.

In tilese experiments both $n$ - and $p$-type silicon having $2 \mathrm{ohm} \mathrm{cm}$ resistivity were used. Here we discuss only the work on $p$ type silicon though similar results have been obtained on the $n$ type material. First the back contact to the wafer was made by aluminum evaporation and alloying which is covered by acid resistant wax. The anodization was carried out in $48 \% \mathrm{HF}$ :ethanol (1:1) solution using $\mathrm{Pt}$ electrode as cathode keeping the current density between 10 to $15 \mathrm{~mA} / \mathrm{cm}^{2}$. Phosphorous was diffused at $850^{\circ} \mathrm{C}$ for $30 \mathrm{~min}$ from a $\mathrm{POCl}_{3}$ source. To measure the electrical properties of porous silicon, $5 \mathrm{~mm}$ diam $\mathrm{Ti} / \mathrm{Ag}$ contacts were evaporated through metal mask.

Preliminary observation of photoluminescence was carried out by placing the sample in ultraviolet light. The undiffused samples gave a bright orange or red glow as usual. The photoluminescence spectra were taken by exciting with a $488 \mathrm{~nm} \mathrm{Ar}$ laser beam varying the power from 20 to $200 \mathrm{~mW}$. The typical photoluminescence shown by solid line in figure 1 extends over a side range from 600 to $850 \mathrm{~nm}$ with peak at $725 \mathrm{~nm}$ for $p$-type PSi. This spectrum is common for this material.

It is commonly observed that heat treatment of PSi to about $300^{\circ} \mathrm{C}$ kills the photoluminescence. This was also observed in the present study. If diffusion is carried out to form $p^{+} p$ or $n^{+} n$ structures no photoluminescence is observed. However when the heat treatment is accompanied by counterdoping to form $n^{+} p$ or $p^{+} n$ structures, photoluminescence remains. The spectrum consists of a sharp peak as shown by dashed line in figure 1 . This is the first report of this observation.

Next we form contacts to the PSi junction diode to observe electroluminescence. A prober was used to pass current of about $500 \mathrm{~mA}$ at $10 \mathrm{~V}$ to observe red light up 


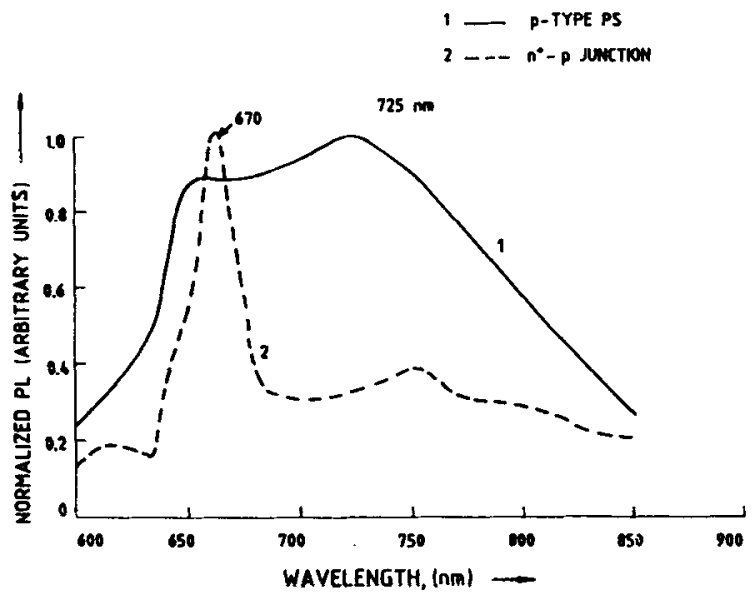

Figure 1. Photoluminescence spectrum of as-processed $p$ type porous silicon (solid line) and after phosphorus diffusion (dashed line).

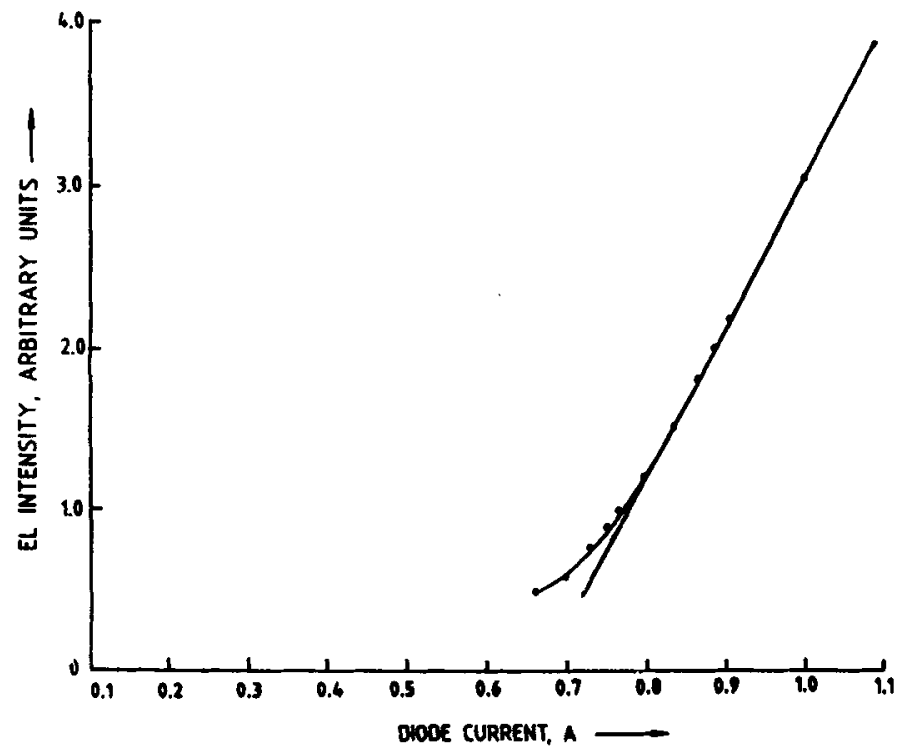

Figure 2. Electroluminescence intensity as function of forward current.

to $5 \mathrm{~h}$ from one sample. The light intensity measured with a photodiode is proportional to the forward current as shown in figure 2. This is the first fabrication of red light emitting diode with stable characteristics using diffused junction. Earlier observations of electroluminescence (Namavar et al 1992) in ITO-PSi-Si Schottky barrier like structures have been feeble and unstable.

We have carried out several other characterizations such as conductivity, photoconductivity, SIMS profiling etc as well as variation of process parameters to understand the phenomenon of photoluminescence from the diffused junction. We believe that the photoluminescence from the as-processed PSi is due to the presence of silicon hydride complexes (Prokes et al 1992) while the post-diffusion photoluminescence/ electroluminescence is due to the quantum size effect. The junction which is shallow 
in the silicon substrate serves as the source of minority carriers by injection into the quantum wires where direct recombination takes place to give out light. Details of these studies will be published elsewhere.

\section{Acknowledgement}

We acknowledge continuous help from Mr I C Mathur and Dr R Gulati during this investigation.

\section{References}

Canham L T 1990 Appl. Phys. Lett. 571046

Namavar F, Paul Maruska H and Kalkhoran N H 1992 Appl. Phys. Lett. 602514

Prokes S M, Freitas J A and Searson P C 1992 Appl. Phys. Lett. 603295

Searson P C, McKaulay J M and Prokes S M 1992 J. Electrochem. Soc. 1393373 